\title{
Impact of the International Prognostic Scoring System cytogenetic risk groups on the outcome of patients with primary myelodysplastic syndromes undergoing allogeneic stem cell transplantation from human leukocyte antigen-identical siblings: a retrospective analysis of the European Society for Blood and Marrow Transplantation-Chronic Malignancies Working Party
}

Francesco Onida, ${ }^{1}$ Ronald Brand, ${ }^{2}$ Anja van Biezen, ${ }^{3}$ Michel Schaap, ${ }^{4}$ Peter A. von dem Borne,${ }^{2}$ Johan Maertens, ${ }^{5}$ Dietrich W. Beelen, ${ }^{6}$ Enric Carreras, ${ }^{7}$ Emilio P. Alessandrino,${ }^{8}$ Liisa Volin, ${ }^{9}$ Jürgen H.E. Kuball, ${ }^{10}$ Angela Figuera, ${ }^{11}$ Jorge Sierra, ${ }^{12}$ Jürgen Finke, ${ }^{13}$ Nicolaus Kröger,${ }^{14}$ and Theo de Witte; ${ }^{4}$ for the MDS subcommittee of the EBMT-CMWP

\begin{abstract}
${ }^{1}$ Fondazione IRCCS Ca' Granda Ospedale Maggiore Policlinico and University of Milan, Italy; ${ }^{2}$ University Medical Center, Leiden, the Netherlands; ${ }^{3}$ Chronic Malignancy WP Registry, Leiden, the Netherlands; ${ }^{4}$ Radboud University - Nijmegen Medical Centre, Nijmegen, the Netherlands; ${ }^{5}$ University Hospital of Leuven, Belgium; ${ }^{6}$ University Hospital, Department of Bone Marrow Transplantation, Essen, Germany; ${ }^{7}$ Hospital Clinic, Barcelona, Spain; ${ }^{8}$ Policlinico San Matteo, Pavia, Italy; ${ }^{9} \mathrm{Helsinki}$ University Central Hospital, Finland; ${ }^{10}$ University Medical Centre Utrecht, the Netherlands; ${ }^{11} \mathrm{Hospital}$ de la Princesa, Madrid, Spain; ${ }^{12} \mathrm{Hospital}$ Santa Creu I Sant Pau, Barcelona, Spain; ${ }^{12}$ Department of Medicine-Hematology, Oncology, Freiburg, Germany; and ${ }^{14}$ University Hospital Eppendorf, Hamburg, Germany
\end{abstract}

\section{ABSTRACT}

Acquired chromosomal abnormalities are important prognostic factors in patients with myelodysplastic syndromes treated with supportive care and with disease-modifying therapeutic interventions, including allogeneic hematopoietic stem cell transplantation. To assess the prognostic impact of cytogenetic characteristics after hematopoietic stem cell transplantation accurately, we investigated a homogeneous group of 523 patients with primary myelodysplastic syndromes who have received stem cells from human leukocyte antigen-identical siblings. Overall survival at five years from transplantation in good, intermediate, and poor cytogenetic risk groups according to the International Prognostic Scoring System was 48\%, 45\% and 30\%, respectively $(P<0.01)$. Both the disease status (complete remission $v s$. not in complete remission) and the morphological classification at transplant in the untreated patients were significantly associated with probability of overall survival and relapse-free survival $(P<0.01)$. The cytogenetic risk groups have no prognostic impact in untreated patients with refractory anemia \pm ringed sideroblasts $(P=0.90)$. However, combining the good and intermediate cytogenetic risk groups and comparing them to the poor-risk group showed within the other three disease-status-at-transplant groups a hazard ratio of 1.86 (95\% CI: 1.41-2.45). In conclusion, this study shows that, in a large series of patients with primary myelodysplastic syndromes, poor-risk cytogenetics as defined by the standard International Prognostic Scoring System is associated with a relatively poor survival after allogeneic stem cell transplantation from human leukocyte antigen-identical siblings except in patients who are transplanted in refractory anemia/refractory anemia with ringed sideroblasts stage before progression to higher myelodysplastic syndrome stages.

\section{Introduction}

Myelodysplastic syndromes (MDS) are clonal hematopoietic disorders with heterogeneous clinical presentation, laboratory findings and life expectancies ranging from a few months to several years. Hypomethylating agents have recently been shown to prolong survival in high-risk subcategories of patients. ${ }^{1}$ However, at present, allogeneic hematopoietic stem cell transplantation (HSCT) represents the most active, curative treatment for MDS. ${ }^{2-4}$ After the introduction of reduced intensity conditioning (RIC) regimens, allogeneic HSCT is also considered an option for elderly patients, in whom the incidence of MDS is considerably higher.
Cytogenetic characteristics represent one of the most important factors in determining treatment outcome and survival for MDS patients. ${ }^{5.7}$ Therefore, cytogenetics is included in the International Prognostic Scoring System (IPSS) to predict life-expectancy. ${ }^{8}$ In untreated patients, the IPSS identified three cytogenetic categories associated with significantly different survival. Normal karyotype as well as deletion of chromosome Y, 5q-, and 20q- single abnormalities were considered as a good-risk category; complex karyotypes and abnormalities involving chromosome 7 were considered as a poorrisk category. All other karyotypes were considered intermediate-risk. ${ }^{8}$ IPSS has been accepted as the standard method to predict the risk of death in patients with MDS. The three

(C)2014 Ferrata Storti Foundation. This is an open-access paper. doi:10.3324/haematol.2014.106880

The online version of this article has a Supplementary Appendix.

Manuscript received on March 5, 2014. Manuscript accepted on July 28, 2014.

Correspondence: francesco.onida@unimi.it 
cytogenetic groups categorized by the IPSS were also maintained in the more recent WHO classification-based Prognostic Scoring System (WPSS), which included the need for transfusions among adverse factors to be considered for prognostic classification. ${ }^{9,10}$ More recently, at the University of Texas M.D. Anderson Cancer Center, Kantarjian et al. performed a retrospective study including a very large series of MDS patients and proposed a new prognostic model accounting for events not considered in the original IPSS, with the aim of predicting outcome of any patient with MDS at any time during the course of the disease, regardless of prior therapy. ${ }^{11}$ With regard to the IPPS cytogenetic groups, this model included only the poor-risk category, which, indeed, by Cox regression survival analysis was associated with the highest estimated coefficient. In a previous study, Haase et al. had also suggested the possibility that the prognostic impact of poor cytogenetics within the IPSS was underestimated. ${ }^{5}$

Because IPSS was developed on the basis of data from a large series of patients with primary MDS who were treated with supportive care, these cytogenetic categories might have a different impact on the outcome of MDS patients undergoing allogeneic HSCT. In fact, at least from a theoretical point of view, HSCT represents a treatment strategy that might overcome the adverse outcome of poor cytogenetics.

In the last decade, a few studies have addressed this issue by means of retrospective analyses on patients transplanted for MDS or secondary AML (sAML). ${ }^{12-16}$ Nonetheless, in MDS patients undergoing HSCT from an HLA-identical sibling, the impact of cytogenetics has never been systematically investigated. The aim of this study is to investigate the association of cytogenetics (classified according to the IPSS in three risk categories) with overall survival (OS), relapse-free survival (RFS), relapse incidence (RI), and non-relapse mortality (NRM) in MDS patients undergoing allogeneic SCT from HLA-identical siblings. We restricted the analysis to the cytogenetic risk groups rather than the complete IPSS(-R) scoring systems because the prognostic impact of cytopenias and percentage of marrow blasts is different in patients treated with intensive chemotherapy to that in untreated patients.

\section{Methods}

Data from 1958 patients with MDS or sAML who underwent allograft from HLA-identical siblings between 1981 and 2006 have been reported to the EBMT. (A complete list of participating centers is available in the Online Supplementary Appendix). A selection was made by excluding patients whose primary disease at diagnosis was either unclear or therapy-related MDS with a history of prior chemo-radiotherapy exposure for other malignancies as well as patients who at time of transplant had progressed to AML or patients with missing data on the disease status at transplant. Finally, $15(1.4 \%)$ patients were excluded because of unknown survival status. The final patient group included 1047 patients. Cytogenetics were available in 555 patients (53\%). Survival of this group of patients and the remaining 492 for whom cytogenetic data were not reported were almost identical (Online Supplementary Figure S1), with a Hazard Ratio (HR) comparing "unknown" to "known" of 1.09 (range 0.93-1.28) $(P=0.30)$. This validated the assumption that the subpopulation of patients with known IPSS cytogenetic risk categories can be considered representative of the whole study population with respect to survival.
Finally, since the "good" and "intermediate" cytogenetic risk groups showed almost identical outcome in terms of OS, RFS, RI and NRM, we decided to merge these two groups and report on the contrast of "good/intermediate" versus "poor". This facilitates reporting on interactions since the cytogenetic effect can then be quantified by a single HR.

A complete set of data for all selected variables, including cytogenetics, was available in 523 patients who, therefore, underwent multivariate analyses.

Institutional review board approval was obtained from all participating institutions.

\section{Statistical analysis}

Univariate analyses of outcomes and curve estimates were based on the Kaplan-Meier method as well as on univariate Cox models to obtain univariate HRs. Multivariate analyses were always performed by Cox regression models (used to estimate HR). They estimate the cause-specific HR when analyzing RI and NRM, while in the case of OS and RFS they have the usual interpretation. All time intervals are computed from the time of transplantation. For RI, death is a censoring event; for NRM, the occurrence of a relapse is censoring (competing risk framework). Besides cytogenetic IPSS categories (good + intermediate vs. poor), additional variables in the analyses included the "stage of disease at transplant" [untreated vs. treated in first CR (CR1) vs. treated not in CR1], the FAB classification at transplant (RA/RARS vs. RAEB/CMML vs. RAEB-t), age classes ( $<20$ years $v$ s. $20-29$ years $v$. $30-39$ years $v s$. $40-49$ years $v s$. $>50$ years), the time from diagnosis to transplant ( $<5$ months vs. 5-8 months vs. $>8$ months), calendar year in which the transplant was performed (as a continuous covariate), type of conditioning (standard myeloablative vs. RIC), T-cell depletion (yes vs. no) and the source of stem cells (bone marrow vs. peripheral blood). Kaplan-Meier curves were compared using the two-tailed log rank test. The association of various risk factors with the outcomes (OS, RFS, RI and NRM) was quantified using the HR estimated in the Cox models. Actual multivariate curve estimates for RI and NRM were made using cumulative incidence estimates, taking into account the competing risk structure. ${ }^{17,18}$ To avoid bias due to the confounding effect of different follow-up times, all analyses were censored at a follow up of 60 months from transplant.

Potential interactions of the main risk factor of interest, IPSS cytogenetic category, with all other covariates were tested by adding the interaction terms to the multivariate model and removing those that were not significant in a stepwise backwards manner until only significant interactions remained.

Calculations were performed with SPSS v.20 software. The cumulative incidences were calculated using a macro for competing risks, developed at the Department of Medical Statistics (LUMC).

\section{Results}

\section{Patients' characteristics at HSCT}

The characteristics of the study group (523 patients) are summarized in Table 1 . The patient group was comprised of 301 males (58\%) and 222 females (42\%), with a median age of 43 years (range $0-66$ years). At the time of transplant, $27 \%$ of patients were 50 years of age or older and $55 \%$ were 40 years or older. Forty-two patients (8\%) were 16 -years old or younger. According to the FAB classification, at transplant $35 \%$ of patients were classified as RAEB-t whereas $27 \%$ were classified as low-risk MDS (RA/RARS). Fifty-one percent of patients did not receive 
intensive chemotherapy prior to the conditioning of the transplant procedure (untreated patients), $24 \%$ were in CR1, and $25 \%$ were either refractory, in relapse or with a subsequent CR status.

Peripheral blood was the source of stem cells in $40 \%$ of transplants. RIC regimens had been used in $12 \%$ of patients. Among these, peripheral blood represented the source of hematopoietic stem cells in $95 \%$. Time from diagnosis to transplant was longer than eight months in $37 \%$ of patients, whilst almost one-third of patients were transplanted within five months from diagnosis. Patients

Table 1. Characteristics of the patient study group at transplant $(\mathrm{N}=523)$.

\begin{tabular}{|c|c|c|}
\hline Variable & Number & Percentage \\
\hline $\begin{array}{l}\text { Age, years } \\
\text { Median (range) } \\
<20 \text { years } \\
20-29 \text { years } \\
30-39 \text { years } \\
40-49 \text { years } \\
\geq 50 \text { years }\end{array}$ & $\begin{array}{c}43(0-66) \\
60 \\
60 \\
113 \\
148 \\
142\end{array}$ & $\begin{array}{l}11.5 \% \\
11.5 \% \\
22 \% \\
28 \% \\
27 \%\end{array}$ \\
\hline $\begin{array}{l}\text { Sex } \\
\text { Male } \\
\text { Female }\end{array}$ & $\begin{array}{l}301 \\
222\end{array}$ & $\begin{array}{l}58 \% \\
42 \%\end{array}$ \\
\hline $\begin{array}{l}\text { FAB classification } \\
\text { RA/RARS } \\
\text { RAEB/CMML } \\
\text { RAEB-t }\end{array}$ & $\begin{array}{l}140 \\
199 \\
184\end{array}$ & $\begin{array}{l}27 \% \\
38 \% \\
35 \%\end{array}$ \\
\hline $\begin{array}{l}\text { Disease stage } \\
\text { Untreated } \\
\text { Treated, in CR1 } \\
\text { Treated, not in CR1 }\end{array}$ & $\begin{array}{l}267 \\
126 \\
130\end{array}$ & $\begin{array}{l}51 \% \\
24 \% \\
25 \%\end{array}$ \\
\hline $\begin{array}{l}\text { Source HSC } \\
\text { BM } \\
\text { PB }\end{array}$ & $\begin{array}{l}312 \\
211\end{array}$ & $\begin{array}{l}60 \% \\
40 \%\end{array}$ \\
\hline $\begin{array}{l}\text { T-cell depletion } \\
\text { No } \\
\text { Yes }\end{array}$ & $\begin{array}{l}356 \\
167\end{array}$ & $\begin{array}{l}68 \% \\
32 \%\end{array}$ \\
\hline $\begin{array}{l}\text { Conditioning } \\
\text { Myeloablative } \\
\text { Reduced-intensity }\end{array}$ & $\begin{array}{c}460 \\
63\end{array}$ & $\begin{array}{l}88 \% \\
12 \%\end{array}$ \\
\hline $\begin{array}{l}\text { Time from diagnosis to HSCT } \\
<5 \text { months } \\
5-8 \text { months } \\
>8 \text { months }\end{array}$ & $\begin{array}{l}170 \\
161 \\
192\end{array}$ & $\begin{array}{l}32 \% \\
31 \% \\
37 \% \\
\end{array}$ \\
\hline $\begin{array}{l}\text { IPSS cytogenetics good risk } \\
\text { Normal } \\
-\mathrm{Y} \\
\text { deletion } 5 \mathrm{q} \\
\text { deletion } 20 \mathrm{q} \\
\text { Total }\end{array}$ & $\begin{array}{c}260 \\
1 \\
13 \\
5 \\
279\end{array}$ & $53.5 \%$ \\
\hline $\begin{array}{l}\text { IPSS cytogenetics intermediate } \\
\text { Trisomy } 8 \\
\text { Other single abnormalities } \\
\text { Double abnormalities } \\
\text { Total }\end{array}$ & isk $\begin{array}{c} \\
32 \\
71 \\
25 \\
128\end{array}$ & $24.5 \%$ \\
\hline $\begin{array}{l}\text { IPSS cytogenetics poor risk } \\
\text { Chromosome } 7 \text { abnormalities } \\
\text { Complex ( } \geq 3 \text { abnormalities) } \\
\text { Total }\end{array}$ & $\begin{array}{c}78 \\
38 \\
116\end{array}$ & $22 \%$ \\
\hline
\end{tabular}

CR1: first complete remission; BM: bone marrow; PB: peripheral blood. were classified as cytogenetics good risk according to the IPSS in $53 \%$ of the cases, while intermediate- and poorrisk categories included $24 \%$ and $22 \%$ of patients, respectively (Table 1). The fraction of patients with high-risk cytogenetics was slightly smaller in those who received a RIC than in those who received standard conditioning (16\% vs. $23 \%$, respectively).

\section{Univariate analyses}

The estimated overall and relapse-free survival at five years was $43 \%$ and $38 \%$, respectively; estimated RI and NRM at five years were $25 \%$ and $36 \%$, respectively. At five years, the cumulative incidence of deaths after a relapse was $21 \%$ and the probability of being alive after having experienced a relapse was $5 \%$. The IPSS cytogenetic risk categories were significantly associated with all treatment outcomes (Table 2)

Overall survival at five years from HSCT in good-, inter-
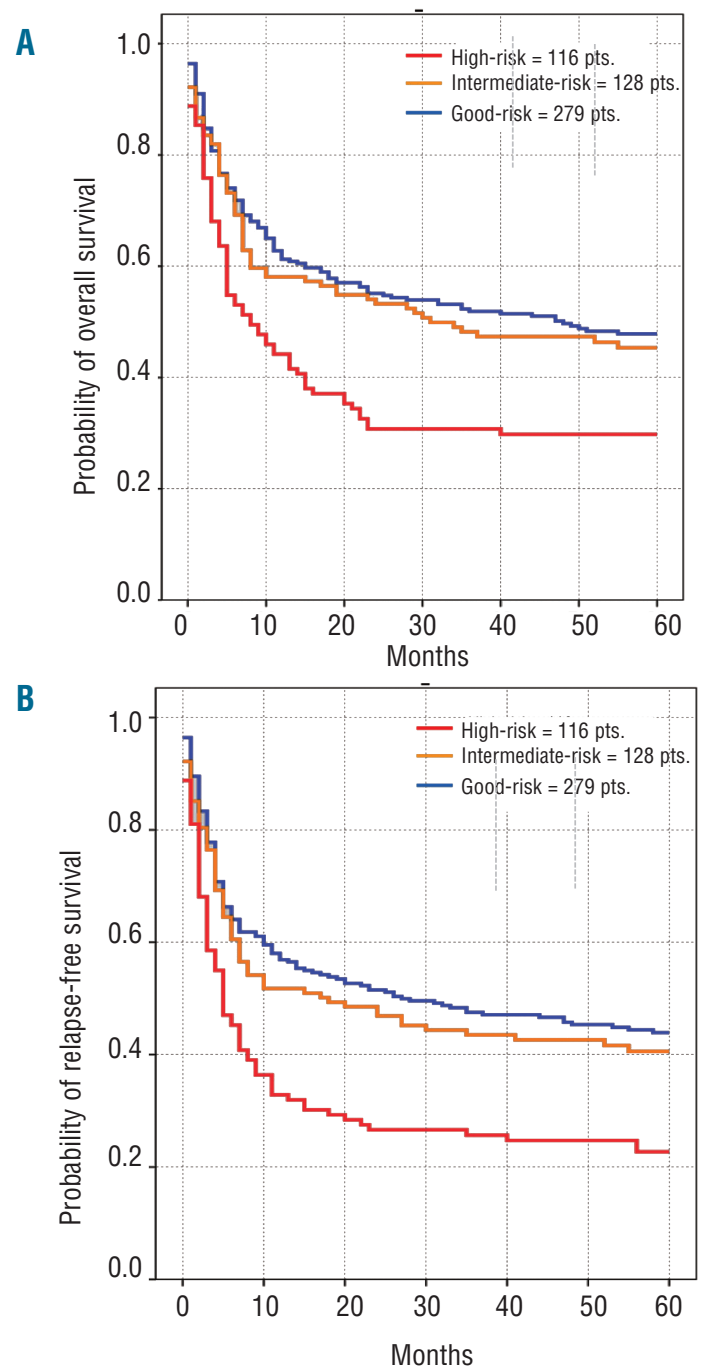

Figure 1. Overall survival $(A)$ and relapse-free survival $(B)$ in the three cytogenetic risk groups (good-risk $=279$ patients, blue line vs. intermediate-risk $=128$ patients, yellow line vs. high-risk $=116$ patients, red line) 
mediate-, and poor-risk groups was $48 \%, 45 \%$ and $30 \%$, respectively $(P<0.01)$. Relapse-free survival at five years from transplant was $44 \%, 41 \%$ and $23 \%$, respectively, in the three cytogenetic risk groups $(P<0.01)$ (Figure 1$)$. These differences were highly significant $(P<0.001$; log rank test $)$ when patients in the poor-risk group were compared to the combined other two risk groups, whereas differences between good and intermediate groups did not reach statistical significance (Figure 1). Therefore, for the rest of the analysis, cytogenetics were re-coded by combining good and intermediate groups as a single risk group ("standard group") to be compared with patients in the poor-risk category to simplify interpretation of the interaction coefficients and to obtain a simple tabular display (Online Supplementary Figure S2).

Disease status at transplant (untreated RA/RARS vs. untreated other disease stages $v s$. treated in CR1 vs. treated not in CR1) was significantly associated with probability of OS and RFS $(P<0.01)$. Patients who were in CR1 had a $46 \%$ probability of being alive and disease-free after five years, compared to $27 \%$ of patients who were not in CR1 after treatment. No difference emerged between untreated patients with less than 5\% marrow blasts and treated patients in CR1. Similar results were documented for OS. There was a significant difference in overall relapse incidence $(P<0.001)$ with the highest probability of relapse in treated patients transplanted without being in CR1 and the lowest in untreated patients with less than $5 \%$ BM blasts. No significant difference in relapse probability was observed between patients treated in CR1 and untreated with RAEB/CMML/RAEB-t. The NRM appeared to be lower in patients transplanted in CR1 in comparison to all

Table 2. Univariate analyses of potentially prognostic factors.

\begin{tabular}{|c|c|c|c|c|c|c|c|c|}
\hline & $0 S^{*}$ & $P\left({ }^{*}\right)$ & RFS" & $P\left({ }^{*}\right)$ & $\mathbf{R}^{*}$ & $P\left({ }^{*}\right)$ & $\mathrm{NRM}^{*}$ & $P\left({ }^{*}\right)$ \\
\hline $\begin{array}{l}\text { FAB untreated } \\
\text { RA/RARS } \\
\text { RAEB/CMML } \\
\text { RAEB-t }\end{array}$ & $\begin{array}{l}51 \% \\
39 \% \\
42 \%\end{array}$ & 0.33 & $\begin{array}{l}46 \% \\
34 \% \\
37 \%\end{array}$ & 0.22 & $\begin{array}{l}15 \% \\
27 \% \\
31 \%\end{array}$ & $<0.01$ & $\begin{array}{l}38 \% \\
39 \% \\
32 \%\end{array}$ & 0.36 \\
\hline $\begin{array}{l}\text { Disease status at HSCT } \\
\text { Untreated RA/RARS } \\
\text { Treated CR1 } \\
\text { Untreated RAEB/RAEBt/CMML } \\
\text { Treated no-CR1 }\end{array}$ & $\begin{array}{l}52 \% \\
51 \% \\
42 \% \\
30 \%\end{array}$ & $<0.01$ & $\begin{array}{l}48 \% \\
46 \% \\
36 \% \\
27 \%\end{array}$ & $<0.01$ & $\begin{array}{l}14 \% \\
24 \% \\
24 \% \\
38 \%\end{array}$ & $<0.01$ & $\begin{array}{l}38 \% \\
30 \% \\
40 \% \\
36 \%\end{array}$ & 0.19 \\
\hline $\begin{array}{l}\text { Cytogenetics } \\
\text { Good risk } \\
\text { Intermediate risk } \\
\text { Poor risk }\end{array}$ & $\begin{array}{l}48 \% \\
45 \% \\
30 \%\end{array}$ & $<0.01$ & $\begin{array}{l}44 \% \\
41 \% \\
23 \%\end{array}$ & $<0.01$ & $\begin{array}{l}22 \% \\
24 \% \\
35 \%\end{array}$ & $<0.01$ & $\begin{array}{l}34 \% \\
35 \% \\
42 \%\end{array}$ & 0.02 \\
\hline $\begin{array}{l}\text { Age class } \\
<20 \text { years } \\
20-29 \text { years } \\
30-39 \text { years } \\
40-49 \text { years } \\
>50 \text { years }\end{array}$ & $\begin{array}{l}58 \% \\
61 \% \\
44 \% \\
38 \% \\
33 \%\end{array}$ & $<0.01$ & $\begin{array}{l}51 \% \\
55 \% \\
39 \% \\
34 \% \\
28 \%\end{array}$ & $<0.01$ & $\begin{array}{l}30 \% \\
19 \% \\
20 \% \\
24 \% \\
32 \%\end{array}$ & 0.05 & $\begin{array}{l}18 \% \\
25 \% \\
41 \% \\
42 \% \\
40 \%\end{array}$ & $<0.0$ \\
\hline $\begin{array}{l}\text { Stem cell source and } \\
\text { conditioning intensity } \\
\text { BM } \\
\text { PB-ablative } \\
\text { PB-reduced intensity }\end{array}$ & $\begin{array}{l}42 \% \\
45 \% \\
42 \%\end{array}$ & 0.64 & $\begin{array}{l}39 \% \\
37 \% \\
38 \%\end{array}$ & 0.98 & $\begin{array}{l}23 \% \\
30 \% \\
34 \%\end{array}$ & 0.25 & $\begin{array}{l}38 \% \\
33 \% \\
28 \%\end{array}$ & 0.32 \\
\hline $\begin{array}{l}\text { T-cell depletion } \\
\text { No } \\
\text { Yes }\end{array}$ & $\begin{array}{l}46 \% \\
37 \%\end{array}$ & 0.09 & $\begin{array}{l}42 \% \\
31 \%\end{array}$ & 0.03 & $\begin{array}{l}22 \% \\
32 \%\end{array}$ & 0.01 & $\begin{array}{l}36 \% \\
38 \%\end{array}$ & 0.45 \\
\hline $\begin{array}{l}\text { Interval diagnosis-transplantation } \\
<5 \text { months } \\
5-8 \text { months } \\
>8 \text { months }\end{array}$ & $\begin{array}{l}44 \% \\
40 \% \\
45 \%\end{array}$ & 0.82 & $\begin{array}{l}41 \% \\
35 \% \\
39 \%\end{array}$ & 0.79 & $\begin{array}{l}26 \% \\
30 \% \\
21 \%\end{array}$ & 0.33 & $\begin{array}{l}33 \% \\
35 \% \\
40 \%\end{array}$ & 0.24 \\
\hline
\end{tabular}

$\left({ }^{*}\right)$ P-values are based on a log rank test for trend in case of a risk factor with more than 2 categories. In case of 2 categories the likelihood ratio test is taken (almost identical to the log rank test). \#At five years.

Table 3. Subdivision according to treatment prior to the conditioning and percentage of marrow blasts at HSCT.

\begin{tabular}{lccc}
\hline Irreatment prior to condifioning & Status at HSCT & Tarrow blasts (\%) at HSCT \\
Untreated & Untreated RARARS & $<5 \%$ & 104 \\
Treated & CR-1 & $<5 \%$ & 126 \\
\hline Untreated & Untreated RAEB, RAEBt, CMML & $\geq 5 \%$ & 163 \\
Treated & No CR-1 & $\geq 5 \%$ & 130 \\
\hline
\end{tabular}


Table 4. Outcome probabilities at five years (\%)* for patients grouped according to IPSS cytogenetic risk categories (CGs) subdivided by remission-induction treatment outcome prior to the conditioning (CR1 vs. no CR1) and no treatment prior to the conditioning: "untreated" (RA/RARS versus others).

\begin{tabular}{|c|c|c|c|c|c|c|c|c|}
\hline & $\begin{array}{l}\text { Untreated } \\
\text { RA/RARS }\end{array}$ & CR1 & $\begin{array}{c}\text { tandard risk CC } \\
\text { Untreated } \\
\text { no RA/RARS }\end{array}$ & $\begin{array}{l}\text { No } \\
\text { CR1 }\end{array}$ & $\begin{array}{l}\text { Untreated } \\
\text { RA/RARS }\end{array}$ & CR1 & $\begin{array}{l}\text { High risk CGS } \\
\text { Untreated } \\
\text { no RA/RARS }\end{array}$ & No CR1 \\
\hline Relapse* & 12 & 18 & 23 & 38 & 24 & 70 & 26 & 38 \\
\hline NRM* & 39 & 32 & 36 & 32 & 29 & 20 & 53 & 43 \\
\hline Overall survival* & 52 & 55 & 48 & 32 & 53 & 27 & 28 & 23 \\
\hline Relapse-free survival* & 48 & 50 & 41 & 30 & 47 & 10 & 21 & 18 \\
\hline
\end{tabular}

Table 5. Multivariate analysis in all patients except patients with untreated RA/RARS.

\begin{tabular}{|c|c|c|c|c|}
\hline & $H R(\#)$ & $P$ & HR(平) & $P$ \\
\hline \multicolumn{5}{|l|}{ Cytogenetics } \\
\hline Standard risk & 1 & & 1 & \\
\hline Poor risk & $1.84(1.38-2.44)$ & $<0.001$ & $1.64(1.22-2.21)$ & 0.001 \\
\hline Age (per 10 years) & 1.19 (1.07-1.33) & 0.002 & $1.22(1.09-1.37)$ & 0.001 \\
\hline $\begin{array}{l}\text { Status at SCT } \\
\text { Treated, CR1 } \\
\text { Untreated RAEB/CMML/RAEB-t } \\
\text { Treated, no CR1 }\end{array}$ & $\begin{array}{c}1 \\
1.40(1.01-1.95) \\
1.76(1.26-2.45)\end{array}$ & 0.004 & $\begin{array}{c}1 \\
1.34(0.95-1.90) \\
1.77(1.26-2.50)\end{array}$ & 0.005 \\
\hline $\begin{array}{l}\text { T-cell depletion } \\
\text { No } \\
\text { Yes }\end{array}$ & $\begin{array}{c}1 \\
1.37(1.03-1.82)\end{array}$ & 0.03 & $\begin{array}{c}1 \\
1.18(0.88-1.56)\end{array}$ & 0.27 \\
\hline $\begin{array}{l}\text { Source } \\
\text { BM } \\
\text { PB-ablative } \\
\text { PB-reduced intensity }\end{array}$ & $\begin{array}{c}1 \\
0.79(0.56-1.11) \\
0.86(0.53-1.39)\end{array}$ & 0.40 & $\begin{array}{c}1 \\
0.74(0.51-1.06) \\
0.77(0.47-1.26)\end{array}$ & 0.23 \\
\hline
\end{tabular}

"Adjusted also for calendar year (HR=1.02, $P=0.42)$ and interval diagnosis-treatment (HR=0.94, $P=0.44) ;{ }^{*}$ Adjusted also for calendar year (HR=1.02, $\left.P=0.36\right)$ and interval diagnosis-treatment $(H R=0.94, P=0.47)$.

others, although this difference did not reach statistical significance.

Age had a general impact on the outcome of patients undergoing transplant for MDS. The probability of surviving in CR decreased over the age of 30 years in comparison to younger patients, but no significant differences were noted among groups of older classes of age (Table 2).

Regarding the source of HSCs, outcomes of patients transplanted with $\mathrm{PB}$ were similar to those of patients transplanted with BM. No significant differences in survival outcomes were detected among patients who were transplanted less than five months from diagnosis and patients who were transplanted after longer time intervals. In $99 \%$ of the patients who received bone marrow stem cells, the type of conditioning was myeloablative, while $\mathrm{n}$ RIC was used in $32 \%$ of the recipients of peripheral blood stem cells. Therefore, these two variables were stratified in three patient groups: 1) BM as the source of stem cells (including patients who received myeloablative conditioning and patients who received RIC regimen; 2) PB as the source of stem cells following myeloablative conditioning; 3) $\mathrm{PB}$ as the source of stem cells following RIC. This approach allowed us to take both variables into account in all models of the analysis. In the univariate analyses, outcome was similar between these three patient groups (Table 2).

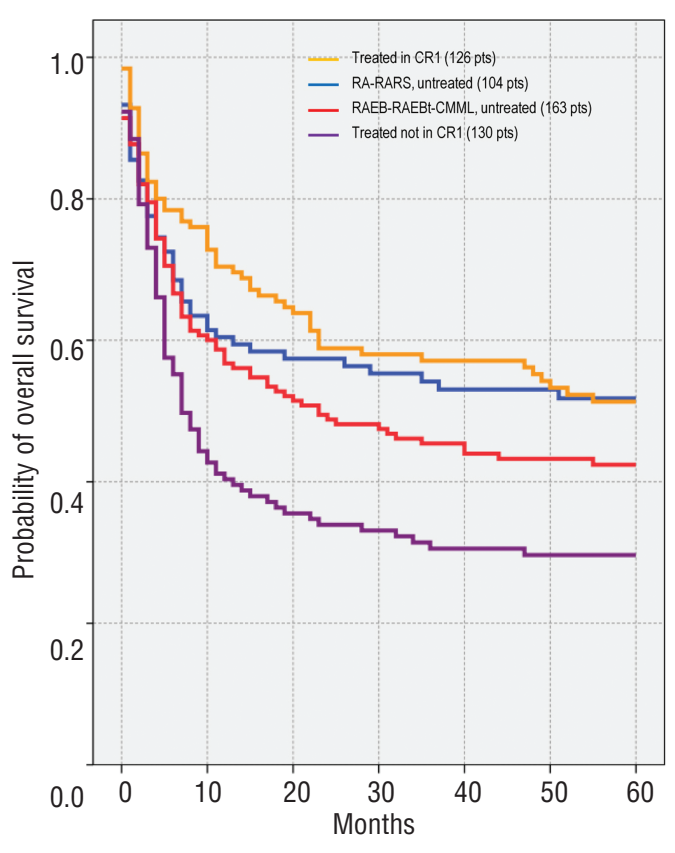

Figure 2. Overall survival according to remission status and percentage of marrow blasts in 104 untreated RA/RARS (blue line) versus 126 MDS (all subtypes) treated in CR1 (yellow line) versus 163 untreated with RAEB, RAEBt, CMML (red line) versus 130 MDS (all subtypes) treated not in CR1 (purple line). 


\section{Prognostic impact of cytogenetic risk groups}

The IPSS cytogenetic risk categories were generally significantly associated with all outcomes (Table 2), but additional studies showed an interaction of the impact of the cytogenetic risk groups and the status of MDS at HSCT (data not shown). Therefore, we decided to investigate the effect of cytogenetics on the outcome of patients in four groups, stratified according to percentage of marrow blasts and status of remission at transplantation (Table 3).

For cross tabulation of FAB classification and disease status at HSCT see Online Supplementary Table S3.

Overall survival of patients stratified in four groups according to remission status and percentage of marrow blasts (Table 3) is shown in Figure 2. Table 4 shows out-
A

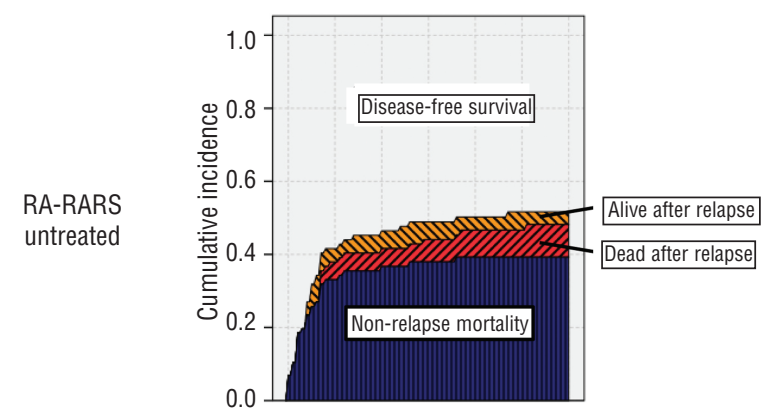

B

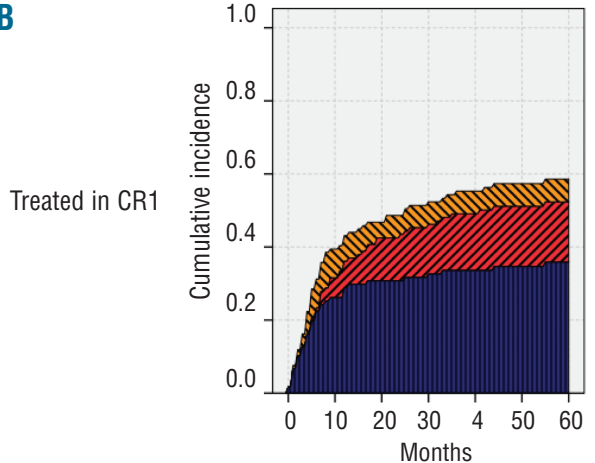

Standard-risk CGs

C

RAEB, RAEB-t, CMML untreated

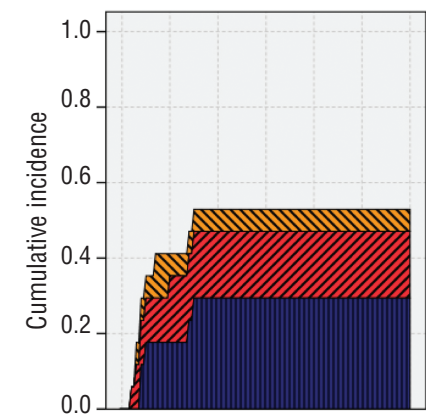

D

reated not in CR1

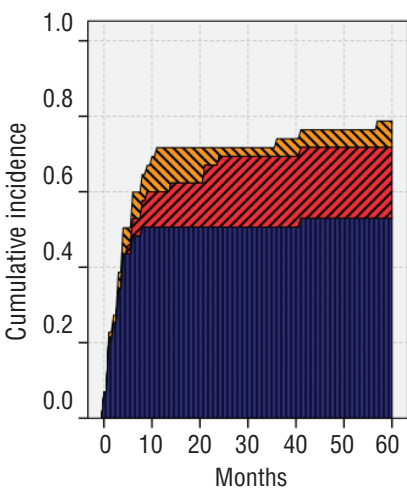

Poor-risk CGs
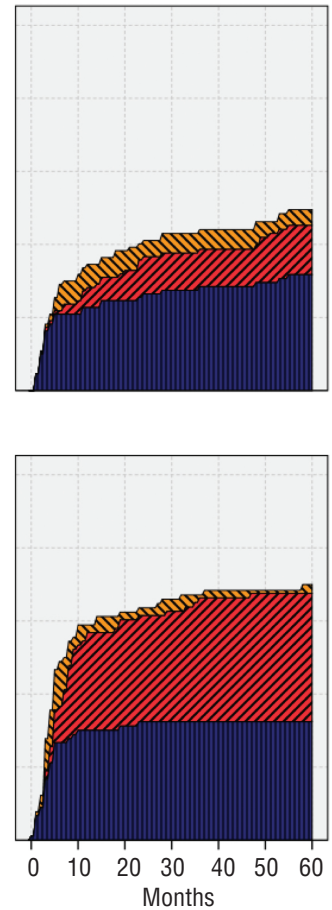

Poor-risk CGs
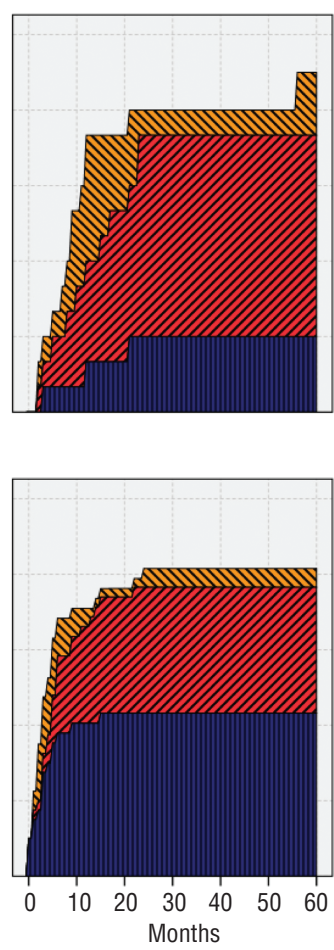

Figure 3. Survival after relapse (yellow), mortality after relapse (red) and non-relapse mortality (blue) in four subgroups, stratified by the disease status at transplant (untreated RA/RARS (A) vs. treated in CR1 (B) vs. untreated RAEB, RAEB-t, CMML (C) vs. treated not in CR1 (D) and cytogenetics (standard-risk in the left panels vs. poor-risk in the right panels). 
come probabilities at five years (\%) for the four groups of patients stratified according to percentage of marrow blasts and status of remission at transplantation both in the standard and in the high IPSS cytogenetic risk groups.

We did not analyze RI and NRM in and between the various subgroups because it would require a full interaction analysis with these competing risk events to establish whether or not these competing risks would actually be different between the subgroups. The interpretation would also depend on the subjective choice of interaction at the hazard level or at the level of the incidence curves themselves. To avoid these over-complicated analyses and interpretations, we restricted ourselves to the simpler and unambiguous end points of OS and RFS, and we computed RI and NRM only for the entire study group.

We observed only small and non-significant differences between the cytogenetic risk categories within the untreated RA/RARS subgroup of patients (Table 4 and Figure $3 \mathrm{~A}$ ) for all outcomes and, therefore, analyzed them separately from the other three subgroups (Table 4 and Figures 3B-D).

\section{Multivariate analyses in all but untreated RA/RARS patients}

Since the cytogenetic risk groups have no prognostic impact in untreated RA/RARS patients, we performed the multivariate analyses on the combined other three subgroups. In this group, poor-risk cytogenetics, disease status at SCT (no CR1), and higher age were all factors independently associated with shorter OS and RFS. In particular for RFS, after adjusting for disease status at SCT and for age, the association of cytogenetics categories showed an HR of 1.84 (95\%CI: 1.38-2.44) for the poor-versus standard-risk patients (Table 5). A significant association with shorter RFS was found for untreated RAEB/CMML/RAEB$\mathrm{t}$ patients in comparison to treated patients in CR1, with an HR of 1.4 (95\%CI: 1.01-1.95) and for patients transplanted with a T-cell depletion strategy (HR 1.37; 95\% CI: 1.03-1.82).

\section{Multivariate analyses in untreated RA/RARS patients}

The multivariate analysis described was repeated for the untreated RA/RARS patients. None of the risk factors used was significant (all $P$ values $>0.20$ ). The effect of poor-risk cytogenetics, adjusted for the other risk factors mentioned in Table 5, for RFS was estimated to be HR=1.04 (95\% CI: $0.5-2.2 ; P=0.91$ ) and for $\mathrm{OS}$ was estimated to be $\mathrm{HR}=1.03$ (95\%CI: 0.48-2.2; $P=0.94$ ).

\section{Discussion}

The results of this retrospective EBMT registry study confirm that allogeneic transplant represents a curative strategy for a significant proportion of patients with MDS. We observed that older age, a disease status other than CR1 at transplant (in those who received any type of induction chemotherapy treatment before the transplant), and more advanced FAB classification in "untreated" patients, represented factors independently associated with significantly shorter overall and relapse-free survival. The impact of age on survival seemed to depend mainly on the increased NRM rather than on the increased risk of disease relapse, in agreement with two previous reports ${ }^{19,20}$ but in contrast with another publication. ${ }^{21}$ The impact of disease stage at transplant is in agreement with other reports. ${ }^{14,16,19}$ Worse survival for patients not in CR1 was mainly a consequence of increased relapse risk. The independent association of the FAB category with relapse probability after allogeneic transplantation confirms earlier reports. $13,14,16,20,21$ The type of conditioning was not a prognostic factor for any of the outcome variables, but the groups were too imbalanced to allow a meaningful multivariate analysis.

The main aim of our study was to analyze the impact of the IPSS cytogenetic risk groups on outcome. Our study clearly shows that poor-risk karyotypes are generally associated with unfavorable outcomes after allogeneic SCT in MDS, as previously reported. . $^{13-16,22}$ No significant differences were detected among IPSS good-risk and intermediate-risk cytogenetic categories. Nevill et al ${ }^{15}$ reported a single institution study consisting of 60 patients including patients with sAML and transplants from unrelated donors. Poor-risk cytogenetics appeared to be predictive of an unfavorable outcome following allogeneic SCT. An updated study from the same group confirmed the negative impact of IPSS poor-risk cytogenetics on event-free survival and relapse in 156 allo-transplanted MDS/sAML patients. ${ }^{16}$ In addition, they suggested the use of donor peripheral blood stem cells to be associated with a more favorable long-term EFS in poor-risk karyotype patients. This latter finding challenges the results of a previous EBMT registry study including only matched sibling transplants for MDS in which patients with poor-risk karyotype did not fare better when the source of stem cells was peripheral blood in comparison to bone marrow. ${ }^{23}$ Armand et al. reported a retrospective analysis on the impact of cytogenetics on outcome of de novo and therapyrelated AML and MDS after allogeneic transplantation. ${ }^{14}$ This study included 74 patients with de novo MDS, while the vast majority had AML. This analysis included a number of patients transplanted from both matched and mismatched unrelated donors. This study also demonstrated a significant association between poor-risk cytogenetics and adverse transplantation outcomes in MDS patients, whereas all other karyotypes were associated with standard outcome. These findings have been recently validated in an independent multicenter cohort of $546 \mathrm{MDS}$ patients, both de novo and therapy-related. This study included a large number of subjects $(43 \%)$ who at the time of transplant had developed AML from an earlier MDS and a majority of transplants from unrelated donors. ${ }^{13}$ Adverse cytogenetics was the strongest prognostic factor for outcome in this large cohort, with a 4-year RFS and OS of $42 \%$ and $46 \%$, respectively, in the standard-risk group, versus $21 \%$ and $23 \%$ in the adverse-risk group. In this analysis, therapy-related disease was not associated with increased mortality after adjustment for cytogenetics.

In our study, we focused on the effect of the three cytogenetic categories, as defined by the IPSS, in a large series of patients who had received allogeneic SCT from HLAidentical siblings only. Median age (43 years) was lower than expected in the current MDS population undergoing SCT, but this study was performed in patients transplanted between 1981 and 2006 and included pediatric patients. Only patients with primary MDS were included in our study because IPSS was derived originally from patients with primary MDS, excluding patients with sAML (transformed MDS) and therapy-related MDS. Therefore, our study also included 185 patients (35\%) classified as RAEB- 
$t$ at the time of transplant. Regardless of these strict selection criteria, the number of patients included in this study is quite large. Given the above mentioned results of our analysis, and also because it has been repeatedly reported that excess blasts at the time of SCT predicts for an increased risk of relapse in $\mathrm{MDS},{ }^{15,19,20}$ an additional investigation of the effect of modifications between cytogenetics and FAB subcategories and disease status at time of transplantation was performed in this study to answer the question as to whether poor-risk cytogenetics remains of prognostic value in the subgroup of patients with less than $5 \%$ marrow blasts. After having merged patients with good- and intermediate-risk cytogenetics in a single group to be compared with the poor-risk group, we could identify a significant interaction between the terms, which led to the observation that the FAB-classification had no predictive value on the outcomes of patients with good- and intermediate-risk cytogenetics, while a strong association was observed among patients with poor-risk karyotypes. Subgroup analysis showed that poor-risk cytogenetic features appeared not to be associated with poor outcome in the $104 \mathrm{RA} / \mathrm{RARS}$ patients who had not received intensive treatment before the conditioning (Table 4). The relapsefree survival in the group with standard-risk cytogenetics was $48 \%$ and in the high-risk cytogenetics group $47 \%$ (Table 4). This was in sharp contrast to the other three subgroups with a 5 -year RFS of $10 \%, 21 \%$ and $18 \%$ in the CR1, untreated non-RA/RARS group, and the no-CR1 group, respectively. The corresponding 5-year RFS in patients with standard-risk cytogenetics were 50\%, 41\% and $30 \%$, respectively (Table 4). The EBMT reported on a larger group of 374 patients transplanted for RA/RARS. ${ }^{24}$ This group consisted of a less homogeneous patient population transplanted with sibling or unrelated donors after standard conditioning or RIC. There was no difference in relapse-free survival (RFS) of the three IPSS cytogenetic risk groups in the 197 patients with known cytogenetic data, as shown by the 4-year RFS of $49 \%, 52 \%$ and $51 \%$ in the good-, intermediate- and high-risk groups, respectively. ${ }^{24}$ In a recent EBMT study, van Gelder et al. ${ }^{25}$ reported on the impact of monosomal karyotype in 277 adult MDS patients treated with HSCT. Fifty patients had untreated RA/RARS at HSCT, but only 8 patients had monosomal karyotype $(\mathrm{MK})$, usually in combination with complex karyotype (CK). Both MK and CK were associated with poor survival after HSCT, but this was not analyzed separately for the RA/RARS patients in view of their low number. In our current study, only 11 patients out of the complete group of 18 patients with high-risk cytogenetics had monosomal karyotype, including 6 patients with complex karyotype. Therefore, we did not analyze this group separately.

The IPSS has recently been revised (IPSS-R) resulting in a new scoring system based on a more elaborate cytogenetic risk classification. ${ }^{26}$ The IPSS-R included five rather than three cytogenetic subgroups with specific and new classifications of a number of less frequent cytogenetic subgroups and prognostic alterations of some other cytogenetic subgroups. The good-risk group, including normal chromosomal pattern, occurs in $72 \%$ of the patients and only $4 \%$ of the patients fall in the very good-risk group (-Y and del 11q). The IPSS-R is based on the outcome of patients treated with supportive care only. The combined poor- and very poor-risk group of the IPSS-R overlaps almost completely with the poor-risk group of the standard IPSS. Median survival of very good and good cytogenetic risk groups was 5.4 years and 4.8 years, respectively, while the median survival in the poor- and very poor-risk groups was 1.5 and 0.7 years, respectively. ${ }^{26}$ Deeg et al. ${ }^{27}$ have studied the impact of the five IPSS-R cytogenetic subgroups of MDS on the outcome after allogeneic SCT. The study included data on 1007 patients transplanted with histocompatible sibling donors and other donors. In the multivariate regression model for overall mortality, only the very poor-risk group showed an inferior outcome $(P<0.001)$ compared to the large good-risk group. The very poor-risk group overlaps considerably with the standard IPSS poor-risk group with the exception of patients with single monosomy 7 or chromosome 7 abnormalities and one additional abnormality or patients with two chromosomal abnormalities. This study did not analyze the interaction of prognostic impact of the various subgroups and the stage/status of disease at time of SCT.

In conclusion, our study shows that, in a large series of patients with primary MDS, poor-risk cytogenetics as defined by the IPSS is associated with a relatively poor survival after allogeneic SCT from HLA-identical siblings except in patients who are transplanted in RA/RARS before progression. The outcome in patients with poorrisk cytogenetics appears not to benefit from intensive chemotherapy prior to allogeneic stem cell transplantation, even if the patients have been transplanted in CR1. As a direct implication for clinical practice, patients with RA/RARS harboring poor-risk cytogenetic aberrations for whom a suitable HLA-identical sibling is identified should be encouraged to undergo allogeneic stem cell transplantation before progression into a more advanced stage of disease. On the other hand, front-line allogeneic stem cell transplantation from HLA-identical sibling may be recommended in MDS patients with $\geq 5 \%$ marrow blasts and poor-risk cytogenetics.

\section{Authorship and Disclosures}

Information on authorship, contributions, and financial \& other disclosures was provided by the authors and is available with the online version of this article at www. haematologica.org.

\section{References}

1. Fenaux P, Ades L. Review of azacitidine trials in Intermediate-2-and High-risk myelodysplastic syndromes. Leuk Res. 2009;33 Suppl 2:S7-11.

2. Witherspoon RP, Deeg HJ. Allogeneic bone marrow transplantation for secondary leukemia or myelodysplasia.
Haematologica. 1999;84(12):1085-7.

3. Witherspoon RP, Deeg HJ, Storer B, Anasetti C, Storb R, Appelbaum FR. Hematopoietic stem-cell transplantation for treatment-related leukemia or myelodysplasia. J Clin Oncol. 2001; 19(8):2134-41

4. Yakoub-Agha I, de La Salmoniere P, Ribaud P, Sutton L, Wattel E, Kuentz M, et al. Allogeneic bone marrow transplantation for therapy-related myelodysplastic syndrome and acute myeloid leukemia: a longterm study of 70 patients-report of the French society of bone marrow transplantation. J Clin Oncol. 2000;18(5):963-71.

5. Haase D, Germing U, Schanz J, et al Evidence for an underestimation of the prognostic impact of poor cytogenetics within the IPSS. Blood. 2006;108:79a.

6. Mufti GJ, Stevens JR, Oscier DG, Hamblin 
TJ, Machin D. Myelodysplastic syndromes: a scoring system with prognostic significance. Br J Haematol. 1985;59(3):425-33.

7. Sole F, Luno E, Sanzo C, Espinet B, Sanz GF, Cervera J, et al. Identification of novel cytogenetic markers with prognostic significance in a series of 968 patients with primary myelodysplastic syndromes. Haematologica. 2005:90(9):1168-78.

8. Greenberg P, Cox C, LeBeau MM, Fenaux P, Morel P, Sanz G, et al. International scoring system for evaluating prognosis in myelodysplastic syndromes. Blood. 1997; 89(6):2079-88.

9. Malcovati L, Germing U, Kuendgen A, Della Porta MG, Pascutto C, Invernizzi R, et al. Time-dependent prognostic scoring system for predicting survival and leukemic evolution in myelodysplastic syndromes. J Clin Oncol. 2007;25(23):3503-10.

10. Alessandrino EP, Della Porta MG, Bacigalupo A, Van Lint MT, Falda M, Onida F, et al. WHO classification and WPSS predict posttransplantation outcome in patients with myelodysplastic syndrome: a study from the Gruppo Italiano Trapianto di Midollo Osseo (GITMO). Blood. 2008;112(3):895-902

11. Kantarjian H, O'Brien S, Ravandi F, Cortes J, Shan J, Bennett JM, et al. Proposal for a new risk model in myelodysplastic syndrome that accounts for events not considered in the original International Prognostic Scoring System. Cancer. 2008;113(6):1351-61

12. Appelbaum FR, Anderson J. Allogeneic bone marrow transplantation for myelodysplastic syndrome: outcomes analysis according to IPSS score. Leukemia. 1998;12 Suppl 1:S25-9.

13. Armand P, Deeg HJ, Kim HT, Lee H, Armistead P, de Lima M, et al. Multicenter validation study of a transplantation-specific cytogenetics grouping scheme for patients with myelodysplastic syndromes. Bone Marrow Transplant. 2010:45(5):877-85.

14. Armand P, Kim HT, DeAngelo DJ, Ho VT, Cutler CS, Stone RM, et al. Impact of cyto- genetics on outcome of de novo and therapy-related AML and MDS after allogeneic transplantation. Biol Blood Marrow Transplant. 2007;13(6):655-64

15. Nevill TJ, Fung HC, Shepherd JD, Horsman DE, Nantel SH, Klingemann HG, et al. Cytogenetic abnormalities in primary myelodysplastic syndrome are highly predictive of outcome after allogeneic bone marrow transplantation. Blood. 1998;92(6):1910-7.

16. Nevill TJ, Shepherd JD, Sutherland HJ, Abou Mourad YR, Lavoie JC, Barnett MJ, et al. IPSS poor-risk karyotype as a predictor of outcome for patients with myelodysplastic syndrome following myeloablative stem cell transplantation. Biol Blood Marrow Transplant. 2009;15(2):205-13

17. Klein JP, Rizzo JD, Zhang MJ, Keiding N Statistical methods for the analysis and presentation of the results of bone marrow transplants. Part 2: Regression modeling. Bone Marrow Transplant. 2001; 28(11):1001-11

18. Klein JP, Rizzo JD, Zhang MJ, Keiding N. Statistical methods for the analysis and presentation of the results of bone marrow transplants. Part I: unadjusted analysis. Bone Marrow Transplant. 2001;28(10):909-15.

19. de Witte T, Hermans J, Vossen J, Bacigalupo A, Meloni G, Jacobsen N, et al. Haematopoietic stem cell transplantation for patients with myelo-dysplastic syndromes and secondary acute myeloid leukaemias: a report on behalf of the Chronic Leukaemia Working Party of the European Group for Blood and Marrow Transplantation (EBMT). Br J Haematol. 2000;110(3):620-30

20. Sierra J, Perez WS, Rozman C, Carreras E, Klein JP, Rizzo JD, et al. Bone marrow transplantation from HLA-identical siblings as treatment for myelodysplasia. Blood. 2002;100(6):1997-2004

21. Sutton L, Chastang C, Ribaud P, Jouet JP, Kuentz M, Attal M, et al. Factors influencing outcome in de novo myelodysplastic syndromes treated by allogeneic bone marrow transplantation: a long-term study of 71 patients Societe Francaise de Greffe de Moelle. Blood. 1996;88(1):358-65

22. Deeg HJ, Storer B, Slattery JT, Anasetti C, Doney KC, Hansen JA, et al. Conditioning with targeted busulfan and cyclophosphamide for hemopoietic stem cell transplantation from related and unrelated donors in patients with myelodysplastic syndrome. Blood. 2002;100(4):1201-7.

23. Guardiola P, Runde V, Bacigalupo A, Ruutu $\mathrm{T}$, Locatelli F, Boogaerts MA, et al Retrospective comparison of bone marrow and granulocyte colony-stimulating factormobilized peripheral blood progenitor cells for allogeneic stem cell transplantation using HLA identical sibling donors in myelodysplastic syndromes. Blood. 2002; 99(12):4370-8.

24. de Witte T, Brand R, van Biezen A, Mufti G Ruutu T, Finke J, et al. Allogeneic stem cell transplantation for patients with refractory anaemia with matched related and unrelated donors: delay of the transplant is associated with inferior survival. Br J Haematol. 2009;146(6):627-36.

25. van Gelder M, de Wreede LC, Schetelig J, van Biezen A, Volin L, Maertens J, et al Monosomal karyotype predicts poor survival after allogeneic stem cell transplantation in chromosome 7 abnormal myelodysplastic syndrome and secondary acute myeloid leukemia. Leukemia. 2013; 27(4)879-88.

26. Greenberg PL, Tuechler H, Schanz J, Sanz G, Garcia-Manero G, Sole F, et al. Revised international prognostic scoring system for myelodysplastic syndromes. Blood. 2012 120(12):2454-65

27. Deeg HJ, Scott BL, Fang M, Shulman HM, Gyurkocza B, Myerson D, et al. Five-group cytogenetic risk classification, monosomal karyotype, and outcome after hematopoietic cell transplantation for MDS or acute leukemia evolving from MDS. Blood. 2012; 120(7):1398-408. 